\title{
Geographic Research in the USGS Western Region
}

\author{
The two geography research \\ programs of the U.S. \\ Geological Survey (USGS), Land \\ Remote Sensing and Geographic \\ Analysis and Monitoring, have \\ very strong relevance to the \\ USGS mission and science \\ strategy. In the western United \\ States, the particular niche of \\ these geography programs is \\ in connecting USGS science to \\ people and communities.
}

Reports from the National Academy of Sciences and other organizations invariably encourage the U.S. Geological Survey (USGS) to ensure the quality of its science while finding ways to make it more relevant to important societal issues. Much of the geography research conducted in the USGS Western Region does exactly that. In Menlo Park, California, the geography research team is focused on developing tools and techniques to help people assess risk from natural hazards and environmental impacts. In Flagstaff and Tucson, Arizo-

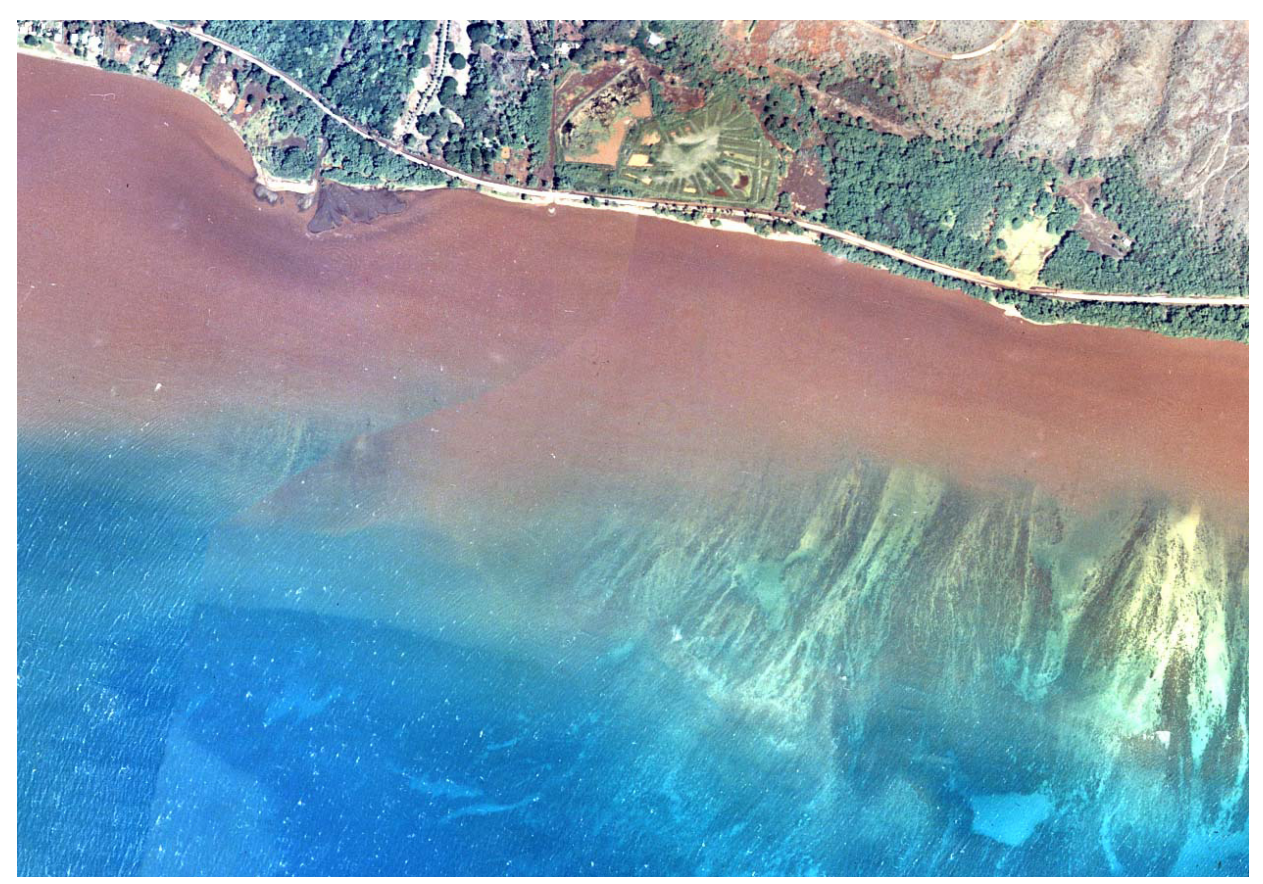

Following a heavy rainstorm, suspended sediment (brown) washed from the land can affect the health of the coral reef off south Moloka'i, Hawai'i. Changes in land-use patterns on the island strongly influence such events.

na, geography scientists explore new ways to use remote sensing to help communities deal with environmental issues.

The Western Geographic Science Center (WGSC) comprises about 50 scientists and support staff, mostly located in Menlo Park, Flagstaff, and Tucson. USGS ge-

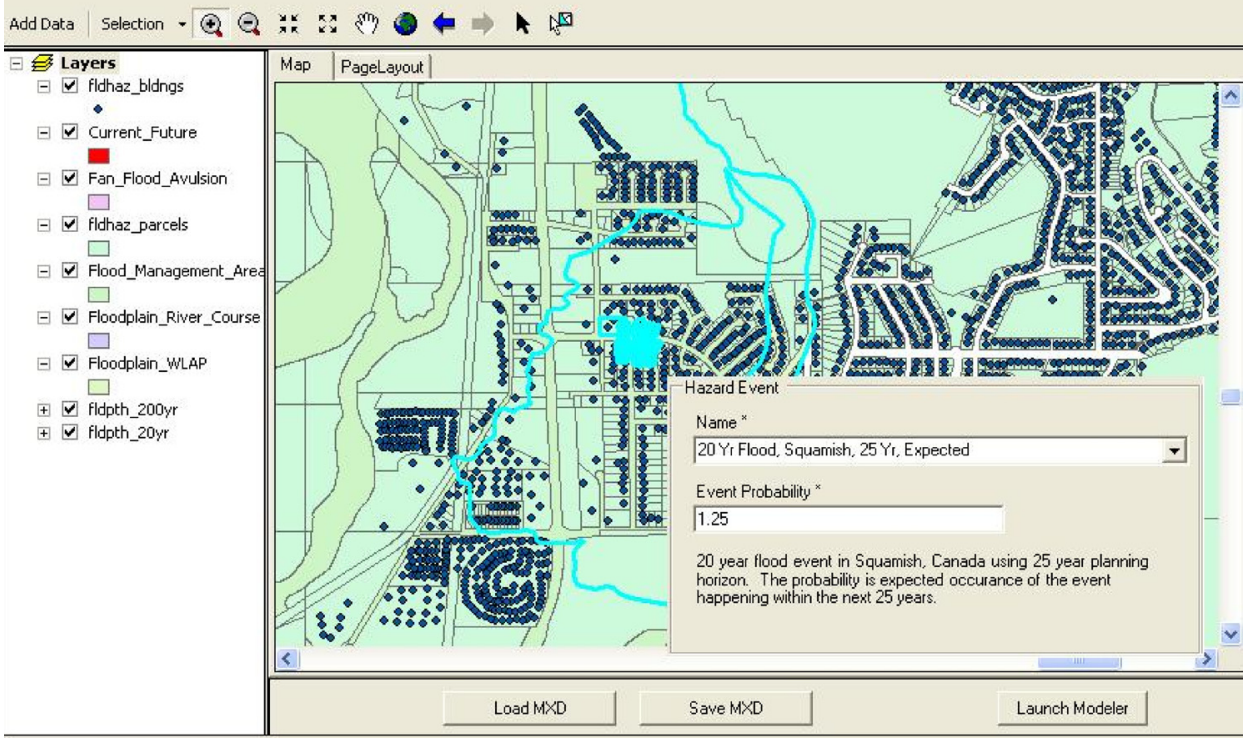

Exit ography research programs also support several scientists in the Alaska Science Center in Anchorage who are developing the National Land Cover Database and assessing environmental changes.

The WGSC is conducting innovative research on how to assess risks to communities from natural hazards, given the uncertainty of scientific knowledge. Data from USGS scientists in the geology, biology, and water resources disciplines is used as input into models that combine that knowledge with measurements of the vulnerability of people and property. These WGSC models develop a risk framework that communities can use to evaluate different mitigation strategies. For example, the Land Use Portfolio Model, developed by WGSC scientists in Menlo Park, takes portfolio theory developed for investors and applies it to assess alternative investments in hazard preparation and mitigation. WGSC scientists are now refining this

Example of the Land Use Portfolio Model being used to assess the risk of flooding in Squamish, British Columbia. Black dots show buildings at risk of flooding in a simulated "20-year flood." 
model and applying it in the USGS MultiHazards Initiative in southern California.

Derivative products from the portfolio model are also being developed to help the National Park Service evaluate park management and restoration decisions in South Florida in the face of rapid urbanization. Economics expertise within the WGSC is enabling a benefit/cost analysis for the USGS Future Land Imaging program. WGSC scientists are strong contributors to the USGS Land Cover Trends project-in the Western Region, 30 years of Landsat data are being used to measure land-cover trends and to determine some of their causative factors and important impacts.

WGSC scientists in Arizona specialize in remote-sensing research and applications, working on issues at the Salton Sea in California, coral reefs in Hawai' $i$, the United States-Mexico border, the Mojave Desert, and other locations. One project with the San Carlos Apache Nation in Arizona involves developing remote-sensing applications and then training members of the tribe how to use those techniques to help manage their natural resources. Another important activity is exploring how remote-sensing systems can measure phenological change-the recurring changes that occur seasonally - as an indicator of various types of environmental changes.

At the Cascades Volcano Observatory in Vancouver, Washington, WGSC is involved in an important project to assess

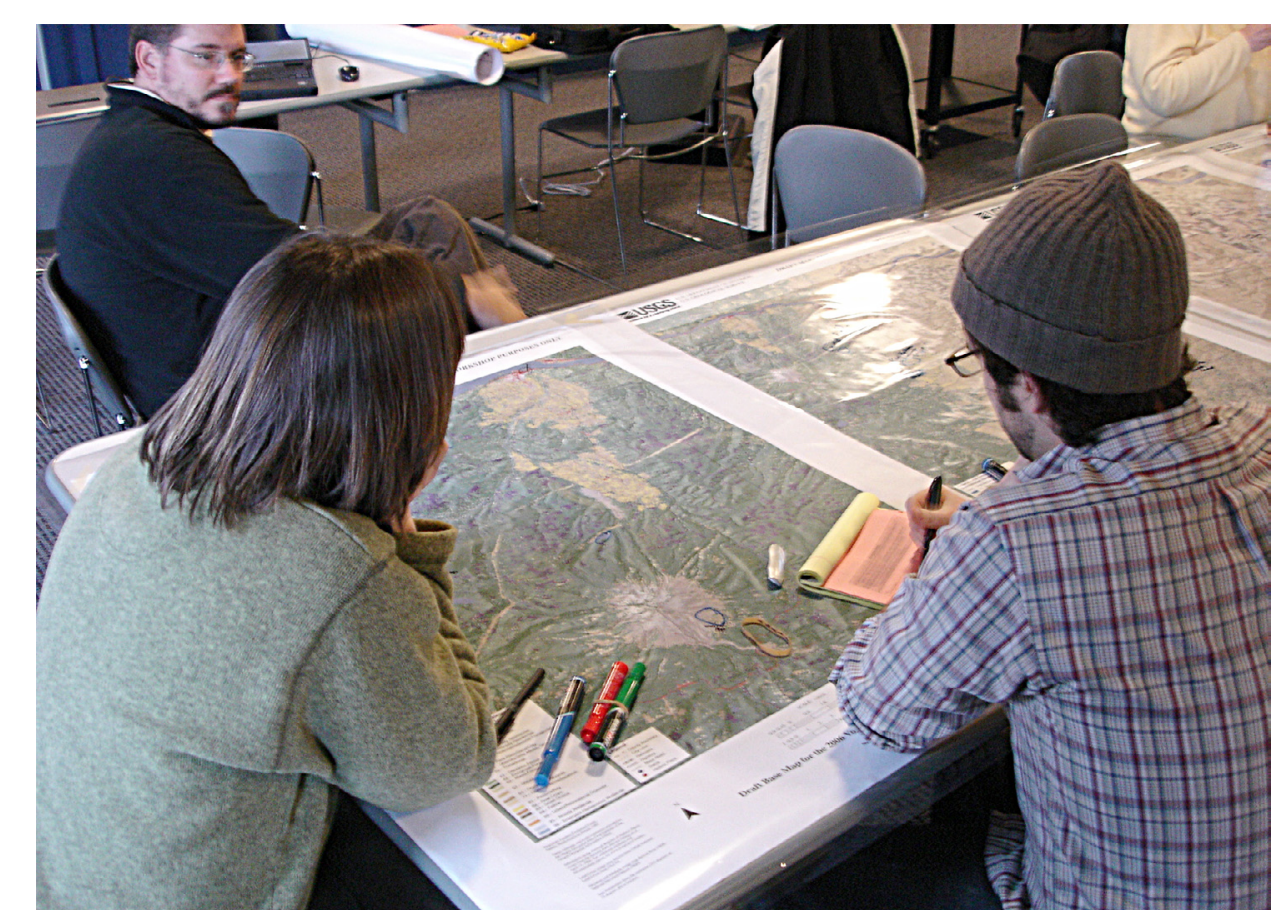

Participants from the local community in a vulnerability assessment workshop in The Dalles, Oregon.
In the photograph above, The cities of Douglas, Arizona, and Agua Prieta, Sonora, straddle the United States-Mexico border. Inset shows sewer pipes from houses extending into a nearby arroyo in Agua Prieta.

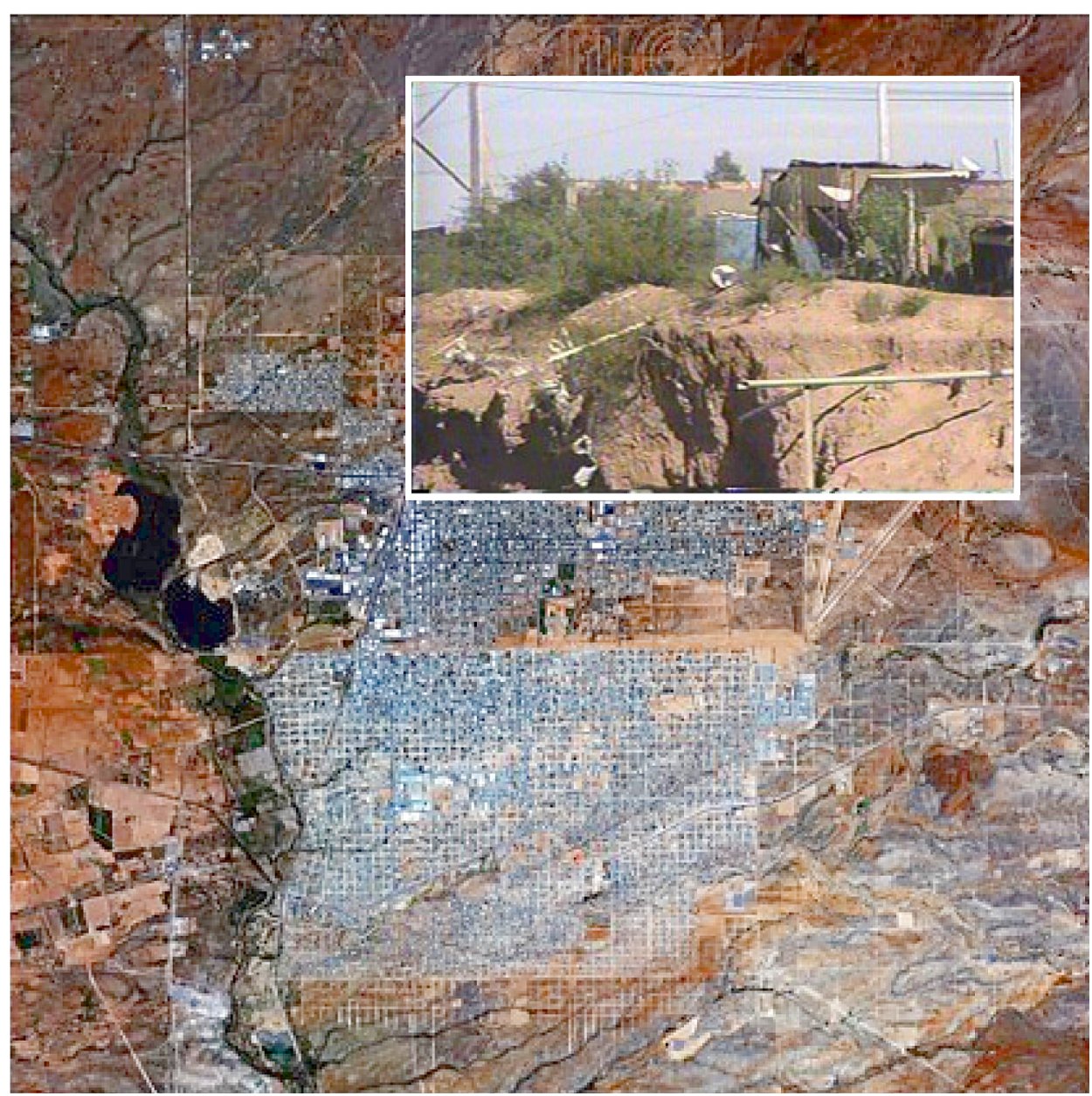

